\title{
Critical Analysis of Children's Drawings as a Diagnostic Tool for Body Schema and Body Image Disorder in Cerebral Palsy
}

\author{
Renée Lampe $^{1,2^{*}}$, Ines Lützow ${ }^{3}$, Tobias Blumenstein ${ }^{2}$, Varvara Turova ${ }^{2}$, Ana Alves-Pinto² \\ ${ }^{1}$ Markus Würth Foundation, Orthopedics Department, Clinic "rechts der Isar", Technical University of Munich, Munich, Germany \\ ${ }^{2}$ Research Unit of Buhl-Strohmaier-Foundation for Children Neuro-Orthopedics and Cerebral Palsy, Clinic "rechts der Isar", Technical \\ University of Munich, Munich, Germany \\ ${ }^{3}$ Stiftung ICP München, Munich, Germany \\ Email: *renee.lampe@tum.de
}

How to cite this paper: Lampe, R., Lützow, I., Blumenstein, T., Turova, V. and AlvesPinto, A. (2016) Critical Analysis of Children's Drawings as a Diagnostic Tool for Body Schema and Body Image Disorder in Cerebral Palsy. Neuroscience \& Medicine, 7, 133-148.

http://dx.doi.org/10.4236/nm.2016.74014

Received: September 28, 2016

Accepted: October 31, 2016

Published: November 2, 2016

Copyright $\odot 2016$ by authors and Scientific Research Publishing Inc. This work is licensed under the Creative Commons Attribution International License (CC BY 4.0).

http://creativecommons.org/licenses/by/4.0/

(c) (i) Open Access

\begin{abstract}
Cerebral palsy is a multiple disability manifested by motor deficits and impairments of cognition, language, and body perception. To assess if body schema and body image distortion in children and youth with cerebral palsy can be represented through draw-a-person-test, outcome measure of conscious and subconscious body awareness, visual perception and cognition in two age-matched groups, one with cerebral palsy and other with developmental disability, were collected. The outcome was compared within the two groups and with reference data (healthy population) and correlated with the outcome of draw-a-person test. Decreased scores in the draw-a-person test in subjects with cerebral palsy compared both to subjects with developmental disorders and to healthy population had strongly correlated with decreased scores in visual perception. This suggests that draw-a-person test may provide a preliminary guidance for the assessment of visual perception. No statistically significant effect of cognitive abilities on performance in the draw-a-person test was found. The influence of both conscious and subconscious body awareness on the scores in the drawa-person test was not significant, which confirms that this test alone is not fully reliable to detect the body schema and body image disorder in cerebral palsy.
\end{abstract}

\section{Keywords}

Cerebral Palsy, Draw-a-Person-Test, Body Perception,

Body Representation Disorder

\section{Introduction}

Individuals with Cerebral Palsy (CP) may have issues with perception, cognition and 
behavior, in addition to their motor disorder [1] [2] [3]. In children with CP, motor impairments are often accompanied by deficits in body schema and body image [4]. The body schema is defined [5] as subconscious ideas about the shape and size of the body and the relationship of the parts of the body to each other. The body image is characterized as the conscious representation of the body parts, of relative position between the body parts and as experience with the body limits. The body image involves both the subject's perceptual experience of his/her own body and conceptual understanding of the body in general [6].

The lack of movement in children with cerebral palsy provides only limited opportunities to pick up tactile and kinesthetic information. As a result, deficits in spatial positional relationship and orientation on own body, exist. Difficulties are manifested e.g. in naming of individual body parts, recognizing their function and relative position, deficiencies in sense of position in space like the designation of the front, and back, top and bottom, right and left. These notions are often learned, but cannot be applied safely. Other symptoms that may indicate a failure of the body schema are manifested in efforts to plan and cope with simple everyday actions, such as, e.g., wearing a sweater properly [7] [8].

In this study, we focus on children and youth with $\mathrm{CP}$ and investigate if they present disturbances of body perception and to what extent the Draw-a-Person Test (DPT) may reflect these disturbances when compared to children and youth with Developmental Disability (DD) of different origin.

\section{Material and Methods}

\subsection{Inclusion Criteria}

All procedures followed were in accordance with the Declaration of Helsinki (1964). The experimental procedures were approved by the Ethic Committee of the Faculty of Medicine of the Technical University of Munich. Informed consent was obtained from all subjects, and from parents when necessary, before starting the measurements.

38 children and youths aged from 7 to 15 years (mean age \pm SD, $11.8 \pm 2.7,19$ males and 19 females) were included in the study. Two groups were formed. The first group consisted of 19 subjects diagnosed with CP. The second group consisted of children and youths with DD matched for age with subjects in the first group. The DD-group was chosen intentionally in order to be able to distinguish influences of CP-specific impairments related to motor function and mobility and reduce possible distortions due to great diversity in development. An age-matched healthy control group would have a much higher developmental age. Sociodemographic and clinical characteristics of the participants are presented in Table 1 .

Children and youths with reduction of vision, essential functional limitation in the upper extremities or with the absence of active speech, could not be included in either group. The children of both groups were able to actively speak, understand voice and tasks, use a pencil and had ability to walk with or without aids. 
Table 1. Sociodemographic and clinical characteristics of the participants $(\mathrm{w}=$ women, $\mathrm{m}=$ man).

\begin{tabular}{cccccc}
\hline & CP-group & \multicolumn{3}{c}{ DD-group } \\
\hline Diagnosis & Age & Gender & Diagnosis & Age & Gender \\
\hline Unilateral CP & $10-15$ & $4 \mathrm{w} / 3 \mathrm{~m}$ & & \\
Bilateral CP & $7-15$ & $4 \mathrm{w} / 5 \mathrm{~m}$ & $\begin{array}{c}\text { Learning disability, genetic } \\
\text { syndrome, neurodegenerative }\end{array}$ & $7-15$ & $10 \mathrm{w} / 9 \mathrm{~m}$ \\
Ataxic CP & $11-14$ & $1 \mathrm{w} / 1 \mathrm{~m}$ & syndrome, neurofibromatosis & \\
Dyskinetic CP & 7 & $1 \mathrm{~m}$ & & \\
\hline
\end{tabular}

\subsection{Assessment of Cognitive Abilities (HAWIK-IV)}

The cognitive abilities were assessed with HAWIK-IV [9]. The test is used in individuals aged from 6 - 16 years.

The test was performed by the occupational therapist in a quiet room. Test subjects were instructed about the purpose of the test and knew that they should solve tasks that require precise observation and listening, thinking and concentration. During the test run no disturbance or distraction from the outside could occur. The test person sat opposite the test administrator. The study environment was friendly and cooperative, in order to avoid test anxiety. If the occupational therapist noticed that the child was fatigued in the course of testing and her/his attention was significantly decreased, the test was completed during the second meeting.

\subsection{Assessment of Mobility Level (GMFCS)}

The mobility level of the subjects of the CP- and DD-group was categorized with the Gross Motor Function Classification System (GMFCS).

\subsection{Assessment of Visual Perception (DTVP-2 and DTVP-A)}

DTVP (Developmental Test of Visual Perception) tests are used in pediatrics to assess the visual perception.

The Frostig Developmental Test of Visual Perception is an adaptation of DTVP-2 [10] [11] to German-speaking children [12]. It consists of eight subtests that evaluate visual perception and visuomotor function. The test is used in children aged from 4 years to 10 years 11 months. The implementation takes 30 - 45 minutes. The DTVP-A test [13] [14] consists of six subtests and may be applied to check visual perception and visual motor skills in individuals 11 to 74 years old. The test takes about $25-45$ minutes.

These tests contain Motor-Reduced Visual Perception (MRP) and Visual-Motor Integration (VMI) subtests. Based on scoring in these subtests, General Visual Perception Quotients (GVPQ) is calculated as the measure of visual perception. Also, Motor-Reduced Visual Perception Quotients (MRPQ) and Visual-Motor Integration Quotients (VMIQ) are computed. 


\subsection{Assessment of Body Representation Disorder (BRD)}

Deficits of body schema and body image are difficult to separate [15]. For this reason, the term "body representation disorder" is often used to collectively describe these concepts. The following 3 subtests are usually applied to detect body image disorders but may also reflect deficits of body schema.

\subsubsection{Body Part Pointing and Calling}

Subjects were requested to indicate 21 of their own body parts. Then the person conducting the test asked subjects to point to specific body parts such as the head, belly, mouth, and so on. Then subjects had to close the eyes and identify and say out loud which body part the person conducting the test had touched, for different body parts.

\subsubsection{Spatial Concepts}

To test the awareness of spatial notions such as inside, outside, under, on the top, on the other side, in front, behind, back, over, around, a doll figure was placed in different spatial positions relative to a play house, e.g. inside the house, on the right side of the house, etc., and the subject had to specify the corresponding position.

\subsubsection{Left-Right Orientation}

The subject was asked to raise her/his right or left arm. To reduce the probability of a correct movement by chance, the subject was requested to show some other parts on the left side of the body e.g. her/his left ear.

\subsubsection{Implementation of Everyday Action}

The ability to perform a simple everyday action like dressing a jacket was tested. After dressing the jacket the subject was asked to bring out a handkerchief from his pocket and throw it in a waste container. This test should primarily identify body schema disorders because preconscious processes are decisive for accomplishment of the action steps [6]. However, this test may also in some extent reflect impairment of the body image, since body image contributes to the control of movement, because subjects who are unable to recognize their own body parts and their relation to each other may have difficulties in dressing themselves.

\subsection{Draw-a-Person-Test after Hermann Ziler}

Often the representation of people in children's drawings is considered as an expression of the body schema [16] [17] [18]. As stated by Tarlow [19], disturbances of the body schema and body image in children with cerebral palsy can be revealed in their drawings, especially in drawings of people. The draw-a-person test after Ziler [20] has been since long used in Germany in child psychology practice to measure the level of development and intelligence. According to updated results by Brosat and Tötemeyer [21], the draw-a-person test is particularly suitable for the evaluation of visual perception development in children with developmental disabilities.

In our study, the subjects of both groups were asked to produce two drawings: a self-portrait and an ideal image of themselves (how they would like to look like). It is 
assumed that a person, who paints a self-portrait, reproduces the concept and the knowledge of his own body [22] [23]. The objective of the second picture was to minimize possible wishful thinking when drawing themselves. Both pictures were assessed according to 52 evaluation criteria [21]. Points were assigned to all drawn development features. The total score obtained was converted into Draw-a-Person Age (DPA) as $D P A=$ Number of Points $/ 4+3$.

Using DPA and the physical age (PA) of the test person, Draw-a-Person Quotient (DPQ) reflecting the state of development of the person was calculated as in [21] (p. 15) $D P Q=D P A / P A^{*} 100$.

\subsection{Statistical Analysis}

The data collected were analyzed using the program R STATS for Windows [24], pp. 375-401. It is assumed that data errors are random and, therefore, their treatment is included into statistical algorithms applied. Depending on variables and objectives, Wilcoxon signed-rank test (WT), Kolmogorov-Smirnov test (KST), and Spearman correlation test (SCT) were used. A statistical significance criterion of $p<0.05$ was adopted. Statistical comparison between the two groups was performed by means of the twosided Wilcoxon test. The results of the comparison are represented below as the mean ( \pm standard deviation of the mean) of the CP-group versus the mean ( \pm standard deviation of the mean) of the $\mathrm{DD}$-group. Also, the corresponding $p$-value is given in brackets.

Some results are displayed as a percentage to permit direct comparison.

\section{Results}

\subsection{HAWIK-IV}

The test could be completed by 18 of the 19 subjects in the CP-group. 6 subjects ( $32 \%$ ) showed an average IQ between 85 - 114 (normal value), 4 subjects $(21 \%)$ an IQ between 70 - 84 (below the norm) and in 8 subjects ( $42 \%$ ) an IQ below 69 (well below the norm) was obtained.

In the DD-group, the HAWIK-test revealed normal values in 3 subjects (16\%), values below the normal range in 7 subjects (37\%), and even lower values in 9 subjects (47\%).

Therefore, $63 \%$ of the children with CP and $84 \%$ of the children with DD had IQvalues below the average normal range. The two groups showed no statistical difference in IQ-values (WT, $72.39 \pm 17.93$ vs. $68.79 \pm 17.53 ; \mathrm{p}=0.63$ ).

\subsection{GMFCS}

In the CP-group, 10 subjects (52.6\%) were classified as GMFCS-level II, 6 (31.6\%) as GMFCS III, and $3(15.8 \%)$ as GMFCS IV.

In the DD-group, all subjects were assessed as having GMFCS I.

\subsection{DTVP}

There was no significant difference between the two groups in MRPQ (WT, $78.44 \pm$ 
16.61 vs. $80.33 \pm 16.61 ; \mathrm{p}=0.66)$. In contrast, significant difference was found in VMIQ (WT, $57.17 \pm 14.73$ vs. $74.56 \pm 17.57 ; \mathrm{p}=0.003$ ).

\subsection{BRD}

The results of body representation tests are displayed in Figure 1. In the CP-group, 13 subjects $(68 \%)$ could not identify correctly all tested body parts, whilst 6 subjects (32\%) were able to name all body parts correctly. In the DD-group, only 3 (16\%) of 19 participants could recognize all body parts tested. In both groups, the body parts with a lower percentage of correct responses were the ankles, neck, hips, chin, shoulders, elbows and feet.

In the subtests Spatial Concepts and Left-Right Orientation, no abnormalities were detected either in the CP-group, or in the DD-group.

In the subtest "everyday action", 14 subjects (74\%) of the CP-group were able to complete the task and $5(26 \%)$ were not. Half of the subjects who completed the task carried it out precisely and the half in a different form.

In the DD-group, 17 subjects (89\%) completed the task and in a correct/expected way; 2 subjects (11\%) had difficulties and could not accomplish the task completely.

There was no significant statistical difference between the two groups in the time required to complete the everyday action test (WT, $63.5 \mathrm{~s} \pm 37.11$ vs. $42.88 \mathrm{~s} \pm 18.52 ; \mathrm{p}=$ $0.12)$.

\subsection{DPT}

No significant differences were found between the self-portrait and ideal image, neither

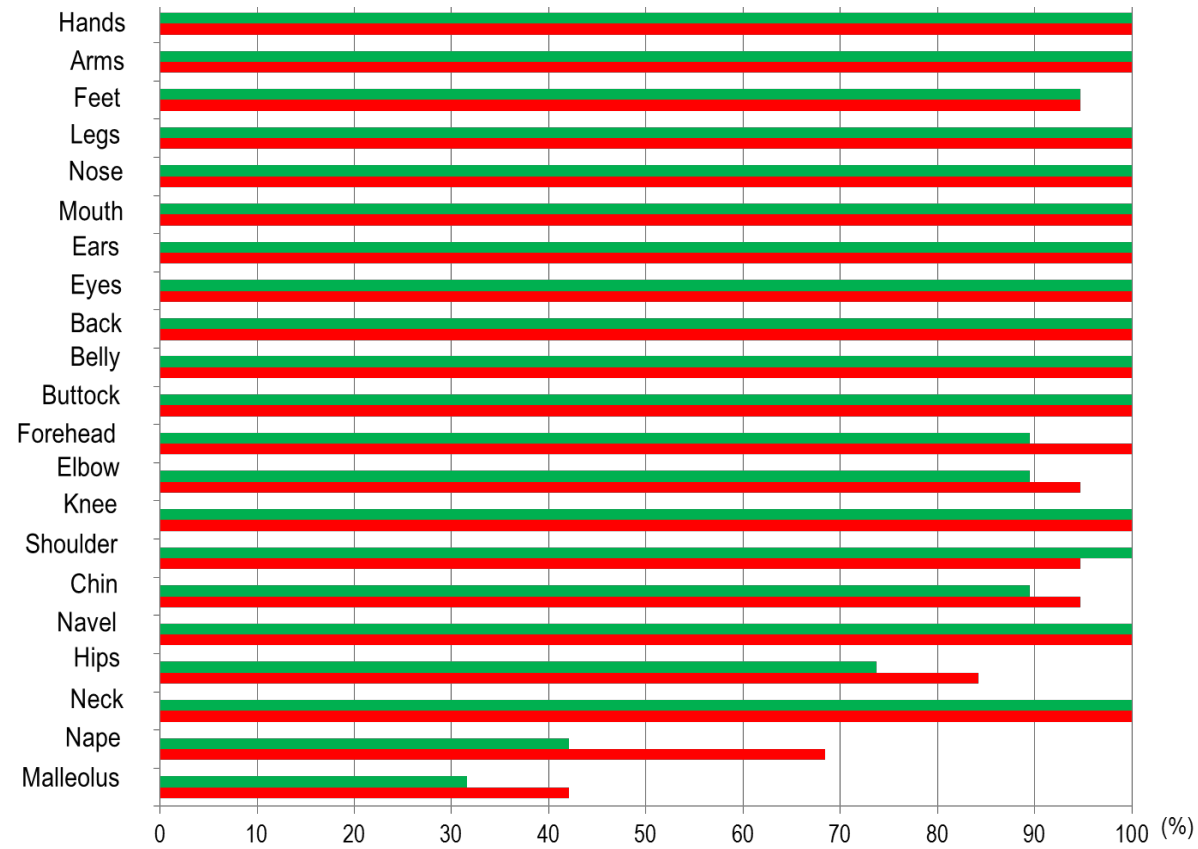

Figure 1. Results of the body part calling test for the CP (in red) and DD (in green) groups, respectively, as percentage of correct answers. 
in the CP-group (KST; $\mathrm{p}=0.526$ ) nor in the DD-group (KST; $\mathrm{p}=0.77$ ). Figure 2 gives an example of two related images for a subject from the CP-group.

Table 2 contains the results of the evaluation of the two drawings (self-portrait and ideal image) for every subject. Using the number of points assigned for the self-portrait, the draw-a-person-age (DPA) is calculated and compared with the physical age (PA), see Figure 3 and Figure 4.

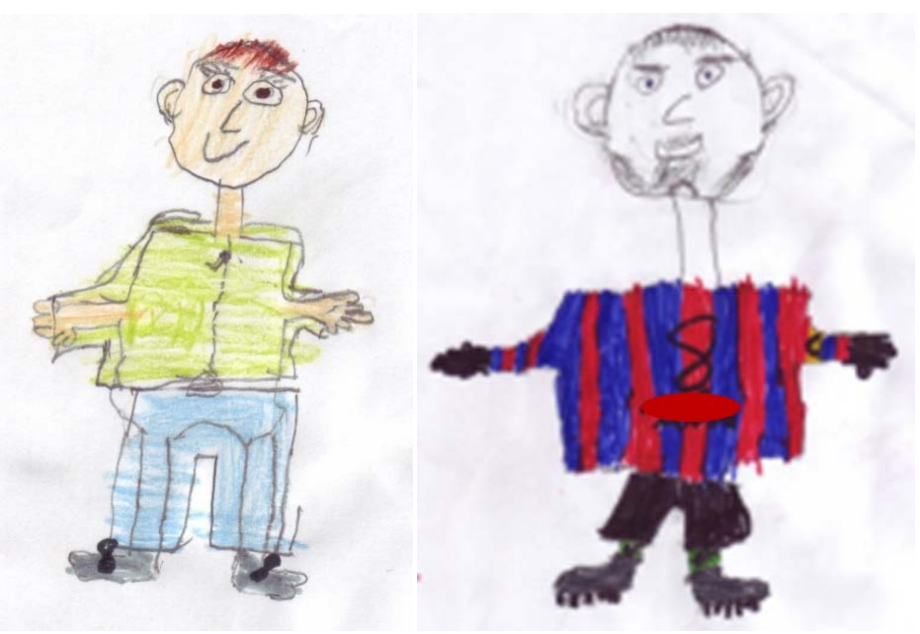

Figure 2. Self-portrait (left) and ideal image (right) drawn by a 14-year-old participant of the CP-group.

Table 2. Scores determined for the self-portrait and ideal image in the CP- and DD-groups, arranged in increasing age order (n.a. = not applicable).

\begin{tabular}{cccccc}
\hline \multicolumn{1}{c}{ CP-group } & \multicolumn{3}{c}{ DD-group } \\
\hline Participant number & Self-portrait & Ideal image & Participant number & Self-portrait & Ideal image \\
\hline 1 & 8 & 7 & 1 & 12 & 12 \\
2 & 12 & 12 & 2 & 13 & 12 \\
3 & 16 & 3 & 3 & 20 & 21 \\
4 & 14 & 5 & 4 & 12 & 11 \\
5 & 23 & 22 & 5 & 13 & 12 \\
6 & 21 & 17 & 6 & 14 & 19 \\
7 & 9 & 6 & 7 & 30 & 29 \\
8 & 15 & 11 & 8 & 14 & 15 \\
9 & 19 & 9 & 9 & 28 & 27 \\
10 & 16 & 12 & 10 & 14 & 12 \\
11 & 25 & 25 & 11 & 16 & 15 \\
12 & 25 & 25 & 12 & 36 & 33 \\
13 & 20 & 21 & 13 & 18 & 18 \\
14 & 25 & 25 & 14 & 26 & 24 \\
15 & 35 & 35 & 15 & 16 & 9 \\
16 & 24 & 17 & 16 & n.a & 8 \\
17 & 11 & 19 & 17 & 13 & 13 \\
18 & 13 & 12 & 18 & 25 & 27 \\
19 & 23 & 23 & 19 & 25 \\
\hline
\end{tabular}




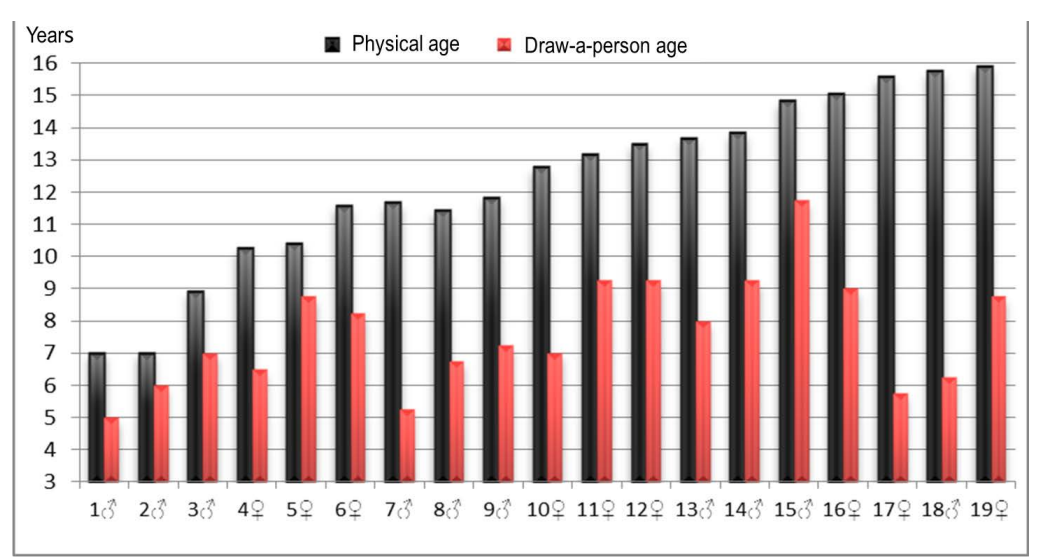

Participant number and gender in CP-group

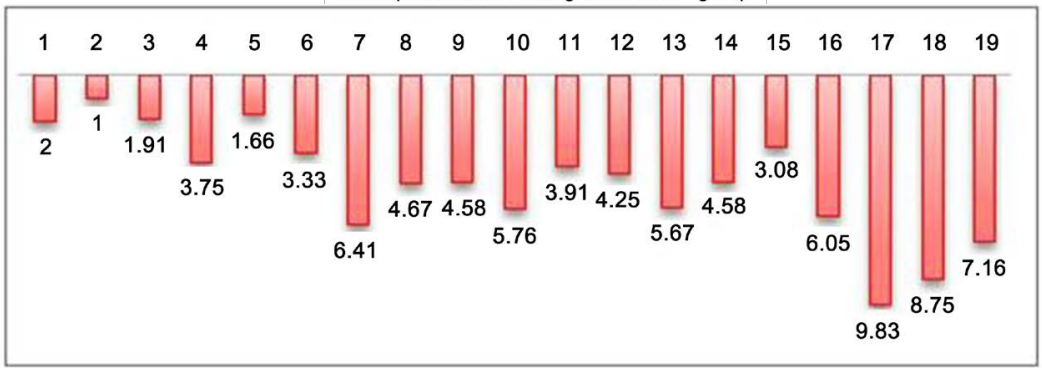

Figure 3. CP-group. Comparison between the physical age (black bars) and the age determined after the draw-a-person test (red bars) for each subject (top). Difference (in decimal numbers) between the physical and draw-a-person age (bottom).

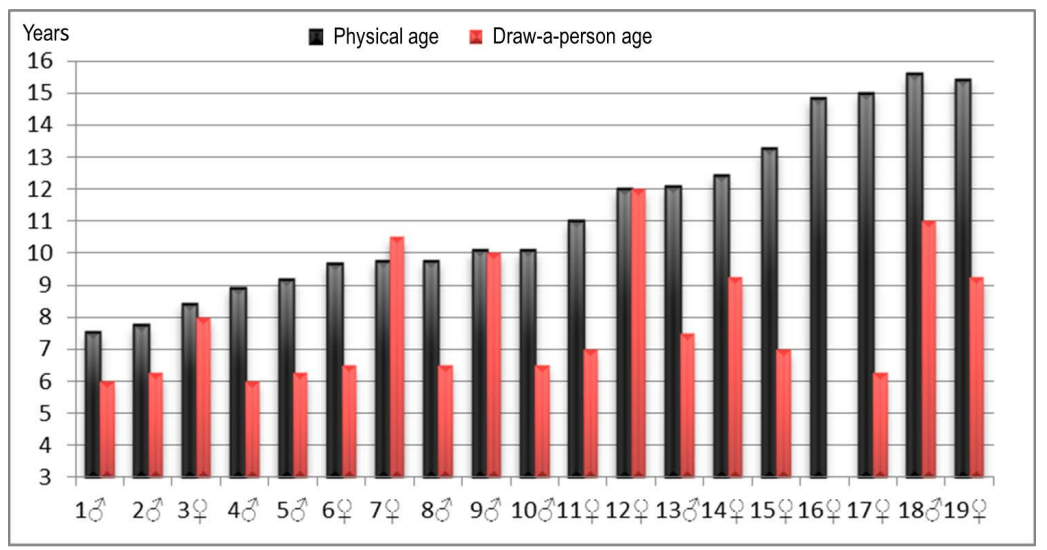

Participant number and gender in DD-group

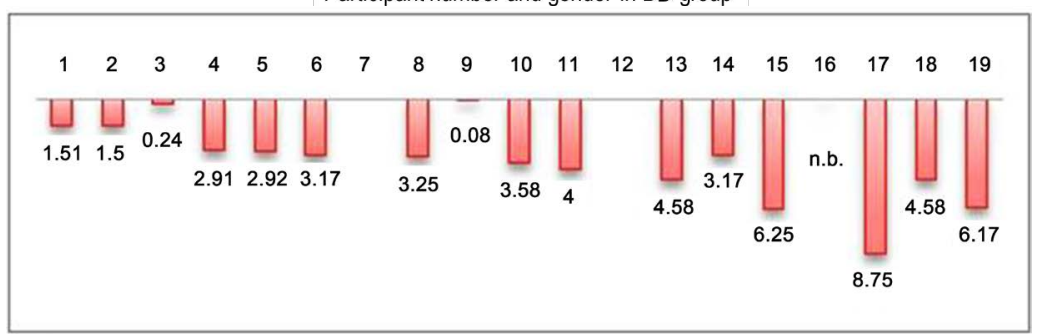

Figure 4. DD-group. Comparison between the physical age (black bars) and the age determined after the draw-a-person test (red bars) for each subject (top). Difference (in decimal numbers) between the physical and draw-a-person age (bottom). 
In the CP-group, the DPA was less than the PA for all of the 19 subjects; the difference between the two is shown in Figure 3.

In the DD-group, apart from a subject for which no results could be obtained, the PA coincided with the DPA in 4 test persons (21\%) and, for the rest of the group, the DPA was lower than the PA (Figure 4).

Statistically, no significant difference was revealed between the two groups in DPA (WT, $7.63 \pm 1.72$ vs. $7.88 \pm 1.95 ; \mathrm{p}=0.81$ ) nor in PA (WT, $12.34 \pm 2.75$ vs. $11.19 \pm 2.62$; $\mathrm{p}=0.15$ ), but a significant difference was obtained for the term [PA-DPA] (deviation of the physical age from the draw-a-person age) (WT, $4.71 \pm 2.45$ vs. $3.32 \pm 2.46 ; \mathrm{p}=0.04$ ).

The DPQ-values were below the norm in the majority of the subjects. Figure 5 and Figure 6 show the computed DPQ (red and green circles, respectively) for each one of the participants. Average normal values for healthy persons (blue circles) of the corresponding age were taken from [21] and are illustrated by blue dots. Admissible standard deviations from these values are marked with black dots. We assumed that young people, 15 and 16 years old, achieve at least the tolerance range of 14-year-olds. A DPQ-value below the tolerance range for the corresponding age and gender indicates a developmental deviation.

In the CP-group, 16 subjects (84\%) had DPQ-values below the norm, 2 subjects (11\%) had values within the permissible tolerance range, and 1 subject (5\%) reached the average reference DPQ-value for the corresponding age (Figure 5). In the DDgroup, 12 subjects (63\%) had DPQ values below the norm, 3 subjects (16\%) had values within the permissible tolerance range, and 3 subjects (16\%) reached the average reference DPQ-value for their age (Figure 6). However, the differences in DPQ values between the two groups were not significant (WT, $63.58 \pm 13.76$ vs. $73.42 \pm 17.46 ; \mathrm{p}=$ $0.12)$.

The DPQ-value depends on the subject's age. The younger the subject is the lower

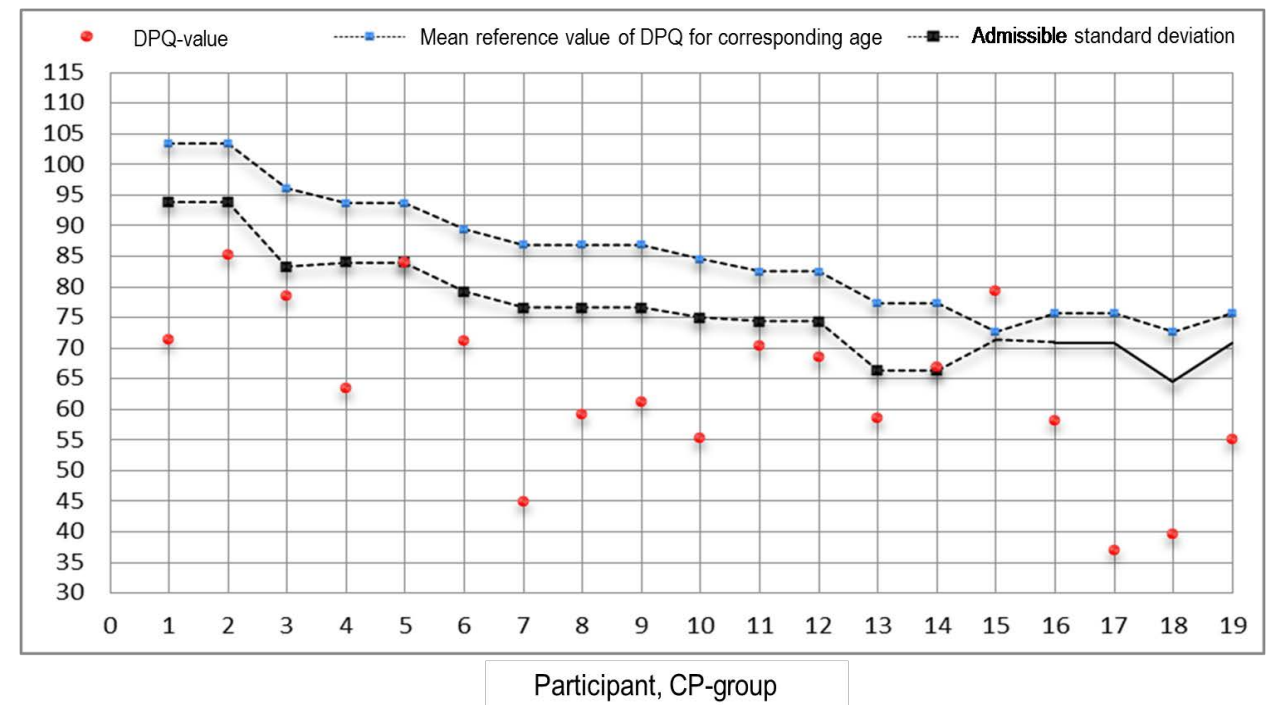

Figure 5. Comparison between DPQ-values obtained for each subject of the CP-group (red dots) and the reference DPQ-values (blue dots) for the corresponding age, as from [21]. 


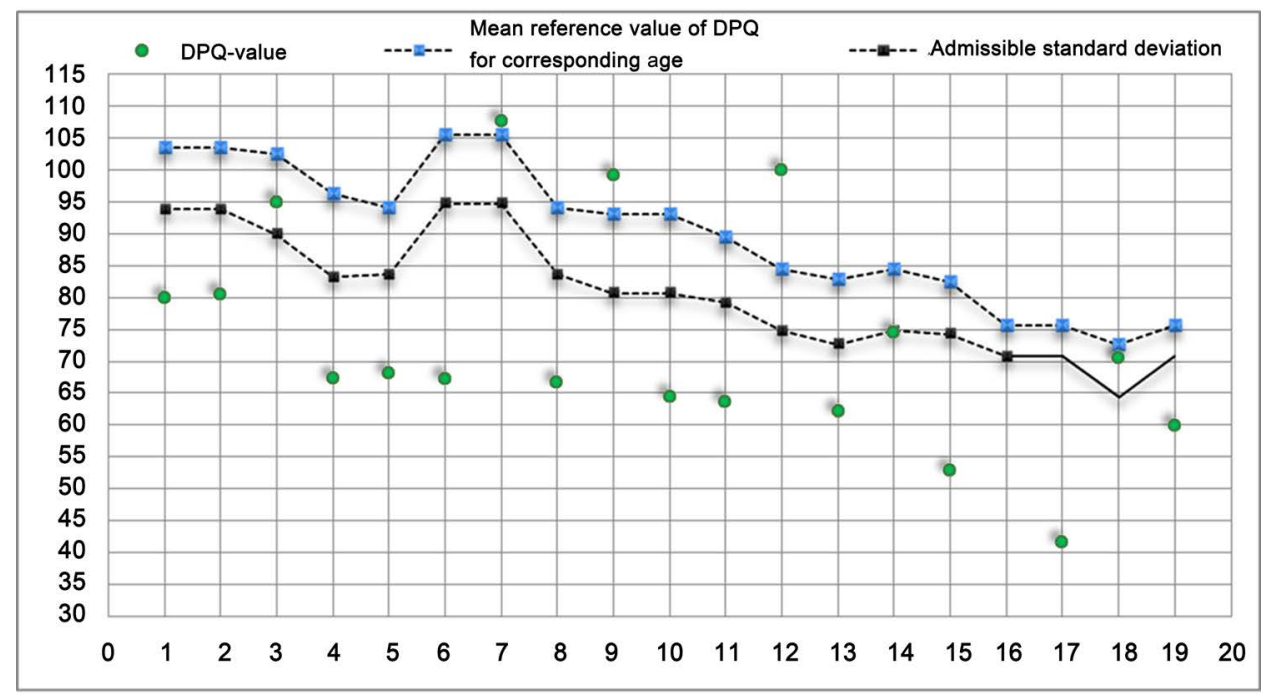

Participant, DD-group

Figure 6. Comparison between DPQ-values obtained for each subject of the DD-group (green dots) and the reference DPQ values (blue dots) for the corresponding age, as from [21].

the expectations for the drawing features being assessed are. The older the subject is, the more detailed the drawing is expected to be. Our results confirm this: The difference to a healthy subject of the same physical age is greater the older the subject is (SCT, $\rho=-0.628 ; \mathrm{p}<0.004$ ).

Average scores of the individual drawing features for the two groups and also for healthy population (according to the data by Brosat and Tötemeyer [21]) are given in Table 3. Though no statistic significant difference was found, nevertheless lower scores were clearly observed in both groups compared to healthy population in the two dimensional drawing of certain features like trunk, arms, fingers, legs, and feet, in the right setting of the neck and legs, in the drawing of lips, face, clothes and correct number of fingers. The CP-group was especially far behind in the drawing of pupils, eyebrows, in the two-dimensional drawing of mouth and ears but was ahead in the representation of chin and elbows. Compared to the DD-group, significantly lower scores were detected for the CP-group in drawing of eyebrows $(\mathrm{p}<0.04)$ and two-dimensional mouth $(\mathrm{p}<0.015)$.

Finally, there was an interesting tendency in average scores of individual drawing features for the subjects with unilateral CP (UL) and those with bilateral CP (BL). The UL-subgroup (7 subjects) had higher average scores compared to the BL-subgroup (9 subjects) in drawing of two-dimensional arms, fingers, legs, and feet. The UL- to BLscores relation on features 23, 29, 33, and 37 (see column 1 in Table 3 for deciphering) was, respectively, 1.6, 2.1, 1.6, and 1.7. However, this result was only of borderline statistical significance $(0.05<\mathrm{p}<0.17)$.

\subsection{Assessment of Correlations}

A significant positive correlation was found in the CP-group between DPA and VMIQ- 
Table 3. Percentage scores of individual features in the draw-a-person test for the CP-group, DD-group and healthy population (as from [21]).

\begin{tabular}{|c|c|c|c|}
\hline Feature & $\mathrm{CP}$-group & DD-group & Healthy \\
\hline 1. Head & $100 \%$ & $94.7 \%$ & $99.8 \%$ \\
\hline 2. Head size & $31.6 \%$ & $31.6 \%$ & $17.1 \%$ \\
\hline 3. Hair & $84.2 \%$ & $94.7 \%$ & $87.4 \%$ \\
\hline 4. Hair distinctly & $0 \%$ & $10.5 \%$ & $18.8 \%$ \\
\hline 5. Eyes & $100 \%$ & $94.7 \%$ & $98.6 \%$ \\
\hline 6. Pupils & $21.1 \%$ & $42.1 \%$ & $56 \%$ \\
\hline 7. Eyebrows & $15.8 \%$ & $42.1 \%$ & $45.1 \%$ \\
\hline 8. Nose & $94.7 \%$ & $84.2 \%$ & $92.1 \%$ \\
\hline 9. Nose in two dimensions & $47.4 \%$ & $31.6 \%$ & $54.9 \%$ \\
\hline 10. Mouth & $100 \%$ & $94.7 \%$ & $96.7 \%$ \\
\hline 11. Mouth in two dimensions & $10.5 \%$ & $42.1 \%$ & $55.5 \%$ \\
\hline 12. Lips & $5.3 \%$ & $5.3 \%$ & $22.7 \%$ \\
\hline 13. Chin & $26.3 \%$ & $5.3 \%$ & $11.3 \%$ \\
\hline 14. Ears & $36.8 \%$ & $52.6 \%$ & $41.2 \%$ \\
\hline 15. Ears in two dimensions & $5.3 \%$ & $10.5 \%$ & $19.7 \%$ \\
\hline 16. Neck & $68.4 \%$ & $68.4 \%$ & $72.7 \%$ \\
\hline 17. Neck in two dimensions & $52.6 \%$ & $52.6 \%$ & $71.1 \%$ \\
\hline 18. Neck set right & $26.3 \%$ & $31.6 \%$ & $49.9 \%$ \\
\hline 19. Trunk & $89.5 \%$ & $94.7 \%$ & $95 \%$ \\
\hline 20. Trunk in two dimensions & $57.9 \%$ & $57.9 \%$ & $80.8 \%$ \\
\hline 21. Shoulder & $26.3 \%$ & $5.3 \%$ & $25.6 \%$ \\
\hline 22. Arms & $94.7 \%$ & $84.2 \%$ & $95 \%$ \\
\hline 23. Arms in two dimensions & $57.9 \%$ & $47.4 \%$ & $83.7 \%$ \\
\hline 24. Arms set right & $31.6 \%$ & $21.1 \%$ & $42.1 \%$ \\
\hline 25. Elbows & $15.8 \%$ & $0 \%$ & $5.3 \%$ \\
\hline 26. Hands & $52.6 \%$ & $68.4 \%$ & $68.4 \%$ \\
\hline 27. Hands distinctly & $26.3 \%$ & $21.1 \%$ & $19.1 \%$ \\
\hline 28. Fingers & $84.2 \%$ & $84.2 \%$ & $84.2 \%$ \\
\hline 29. Fingers in two dimensions & $52.6 \%$ & $47.4 \%$ & $73.1 \%$ \\
\hline 30. Fingers right number & $36.8 \%$ & $31.6 \%$ & $64.5 \%$ \\
\hline 31. Thumbs & $10.5 \%$ & $5.3 \%$ & $6.6 \%$ \\
\hline 32. Legs & $94.7 \%$ & $89.5 \%$ & $92.7 \%$ \\
\hline 33. Legs in two dimensions & $52.6 \%$ & $47.4 \%$ & $78.2 \%$ \\
\hline 34. Legs set right & $10.5 \%$ & $15.8 \%$ & $30.7 \%$ \\
\hline 35. Knee & $0 \%$ & $0 \%$ & $1 \%$ \\
\hline 36. Feet & $84.2 \%$ & $89.5 \%$ & $88.3 \%$ \\
\hline 37. Feet in two dimensions & $47.4 \%$ & $31.6 \%$ & $61 \%$ \\
\hline 38. Feet with heels & $10.5 \%$ & $15.8 \%$ & $17.1 \%$ \\
\hline 39. Face & $15.8 \%$ & $15.8 \%$ & $41.7 \%$ \\
\hline 40. Face complete & $5.3 \%$ & $5.3 \%$ & $5.2 \%$ \\
\hline 41 - 44. Profile face, trunk/arms, leg/foot & $0 \%$ & $0 \%$ & $0.4-0.9 \%$ \\
\hline 45. Headwear & $0 \%$ & $0 \%$ & $6 \%$ \\
\hline 46. Headwear with details & $0 \%$ & $0 \%$ & $0.8 \%$ \\
\hline 47. Clothing & $47.4 \%$ & $47.4 \%$ & $63.4 \%$ \\
\hline 48. Trousers & $5.3 \%$ & $0 \%$ & $21.3 \%$ \\
\hline 49. Skirt & $0 \%$ & $0 \%$ & $8.5 \%$ \\
\hline 50. Collar & $0 \%$ & $0 \%$ & $2.4 \%$ \\
\hline 51. Footwear & $5.3 \%$ & $10.5 \%$ & $40 \%$ \\
\hline 52. Footwear distinctly & $0 \%$ & $5.3 \%$ & $6.8 \%$ \\
\hline
\end{tabular}

Statistical significance $(0.05<\mathrm{p}<0.17)$. 
values (SCT; $\rho=0.4, \mathrm{p}=0.01$ ), and between DPA and MRPQ-values (SCT; $\rho=0.65, \mathrm{p}$ $=0.003)$. In the DD-group only correlation between DPA and MRPQ was established (SCT; $\rho=0.64, \mathrm{p}=0.004$ ). A significant negative correlation between DPA and the time required to complete the everyday action (TEA) was found in the CP-group (SCT; $\rho=$ $-0.62, \mathrm{p}=0.02$ ).

Furthermore, a positive correlation between TEA and GMFCS-level was established (SCT; $\rho=0.747, \mathrm{p}=0.002$ ) in the CP-group. The TEA-values obtained for the subjects who were able to correctly identify their body parts, were shorter than for the subjects who had difficulties in identifying different body parts (WT; $26.4 \pm 18.134 \mathrm{~s}$ against $115.46 \pm 73.765 \mathrm{~s} ; \mathrm{p}<0.002)$. However, awareness of body parts correlated neither with DPA (WT; $\mathrm{p}=0.135$ ), nor with DPQ (WT; $\mathrm{p}=0.37$ ). The latter analysis was not relevant in the $\mathrm{DD}$-group, since only 3 subjects were able to identify all body parts.

A borderline correlation was established in both groups between IQ-values and DPQ-scores in the draw-a-person test (WT; $\rho=0.389, \mathrm{p}=0.11$ for the CP-group; $\rho=$ $0.46, \mathrm{p}=0.05$ for the DD-group).

The deviation PA-DPA correlated strongly positive with PA in both groups (WT; $\rho=$ $0.769, \mathrm{p}=0.0001$ for the CP-group; $\rho=0.674, \mathrm{p}=0.002$ for the DD-group).

No significant correlation between the results in the body part calling test and the scoring of individual features in the draw-a-person test (compare e.g. percentage values for chin, shoulder, knee, and elbow in Figure 1 and Table 3) was found for none of the groups.

\section{Discussion}

As a screening method, which is not expensive and is quite easy to use, the draw-aperson test has been described as useful tool to assess the general level of development of a child [25] [26]. However, scientific studies on drawings of children with CP are very rare [26] [27] [28] [29].

The objective of the present work was to analyze whether distortions of body schema and body image in children with $\mathrm{CP}$ can be detected using the draw-a-person test, and to what extent the outcome of the draw-a-person test can be influenced by scores in visual perception and cognition.

According to Abercrombie and Tyson [27] deviations in the outcome of draw-aperson test in children with CP do not necessarily indicate a disturbance of the body schema, but can reflect instead a general weakness in drawing. In a study with children that were premature babies [29], it was indicated that the drawing ability, besides depending on the motor development and cognition, is also positively influenced by creativity and a stimulating environment [30] [31]. Our study showed that DPA values for children with CP correlated with VMI and MRP. These results suggest that a lower score in the draw-a-person-test is associated with a worse visual perception. The comparison with the DD-group confirmed that the below-average results in the draw-aperson-test in children and youths with CP are due to serious visuomotor distortions. Based on this result, the draw-a-person test could be applied for the preliminary as- 
sessment of visual perception in children with CP.

It was shown in [29] that a developmental delay in premature infants is reflected in the drawing skills. In our study, DPA values were below PA values, in both groups. However, the difference [PA-DPA] was slightly larger in the CP-group compared to the DD-group. This difference correlated positively with physical age in both groups: The older the subject, the larger the difference [PA-DPA]. This suggests that an intensification of rehabilitation activities with increasing age may be important.

Some issues about the influence of intelligence on the performance in the draw-aperson-test are described by Krombholz [23]. In our study, however, no significant impact of the cognitive development assessed with the HAWIK-IV test on the outcomes in the draw-a-person-test was revealed. This is consistent with the results of Brosat and Tötemeyer [21] suggesting that the draw-a-person-test reflects the level of development of visual perception rather than of intelligence.

No significant influence of the body representation disorder on the outcomes in the draw-a-person test was registered. The evaluation of the draw-a-person test and body representation test showed that children and youths with CP had a discrepancy between the actual knowledge of their own body and its pictorial representation. Nevertheless, no significant difference existed in DPA and DPQ between the children with $\mathrm{CP}$ who knew their body parts and their functions, and those who had difficulty in identifying their body parts. Moreover, the majority of the examined children with $\mathrm{CP}$ were able to perform the simple everyday action properly. Children who had completed the action task were not better in the draw-a-person-test than the children who had not completed it. The body representation disorder therefore is not fully reflected in the self-portrait drawing of the children with CP.

That subjects with lower DPA took longer to complete the everyday action test can be explained by deficits in gross motor skills (positive correlation between the time needed to perform the task action and the mobility level). In contrast, fine motor skills and visual perception, seem to play no significant role, since neither DPQ nor VMI correlated with the time required to complete the action task. Some subjects needed more time to complete the action task because of spastic movement disorder. Despite needing more time they nevertheless completed the task correctly, and this reflects a proper action planning. Here the knowledge of the body parts played apparently an essential role: Individuals who were able to identify their body parts without difficulty performed the action task faster than the subjects who had difficulties in determining the different body parts.

According to the results of our study on the suitability of the draw-a-person-test for the detection of body schema and body image disturbances in children with $\mathrm{CP}$, the following statements can be done: 1) Results in the draw-a-person test below the normal average indicate impairments of visual perception; 2) The draw-a-person test alone cannot be used for assessing disturbance of body representation in children with CP; 3) The draw-a-person test is not a suitable method to evaluate cognitive abilities in children with $\mathrm{CP}$. 
Our results on reduced ability of children with bilateral CP (as compared to children with unilateral $\mathrm{CP}$ ) in two-dimensional drawing are in agreement with earlier findings (see e.g. [32]) and indicate that children with bilateral spasticity are more likely to present impairments of visual perception. However, a larger number of subjects would be needed to prove this statistically.

Investigation of the contribution of other diagnostic factors to the outcome of the draw-a-person-test would require extending the study to subjects with ataxic and dyskinetic forms of cerebral palsy. In the study here presented, only 2 children with ataxic $\mathrm{CP}$ and 1 child with dyskinetic $\mathrm{CP}$ agreed to participate and could be included.

\section{Conclusion}

The suitability of the draw-a-person test for the assessment of the body representation disorder in children with cerebral palsy was analyzed. It was observed that poor performance in the draw-a-person test was determined by impairments of visual perception. In addition, preliminary evidence was provided that children with bilateral spasticity are more likely to have impairments of visual perception. The scores obtained in specific tests of body perception had no significant impact on the outcome of the drawa-person test, which implies that the sole implementation of the draw-a-person test cannot provide reliable judgments on body representation deficits in children with $\mathrm{CP}$. The increasing difference between the physical age and the age revealed through the drawing with increasing age should be taken into account when planning rehabilitation for children with developmental disabilities of different origin. A long-term study examining a potential impact of targeted rehabilitation on the results of the draw-a-person-test would be useful and interesting.

\section{Conflict of Interest}

The authors declare that they have no conflict of interest.

\section{References}

[1] Bennet, S.E. and Karnes, J.L. (1998) Neurological Disabilities: Assessment and Treatment. A Wolters Kluwer Company, Philadelphia.

[2] Rosenbaum, P., Paneth, N., Leviton, A., Goldstein, M., Bax, M., Damiano, D., Dan, B. and Jacobsson, B. (2007) A Report: The Definition and Classification of Cerebral Palsy April 2006. Developmental Medicine \& Child Neurology Supplement, 109, 8-14.

[3] Sukhov, A., Wu, Y., Xing, G., Smith, L.H. and Gilbert, W.M. (2012) Risk Factors Associated with Cerebral Palsy in Preterm Infants. Journal of Maternal-Fetal and Neonatal Medicine, 25, 53-57. http://dx.doi.org/10.3109/14767058.2011.564689

[4] Fontes, P.L.B., Moura, R. and Haase, V.G. (2014) Evaluation of Body Representation in Children with Hemiplegic Cerebral Palsy: Toward the Development of a Neuropsychological Test Battery. Psychology \& Neuroscience, 7, 139-149. http://dx.doi.org/10.3922/j.psns.2014.019

[5] Joraschky, P., Loew, T.H. and Röhricht, F. (2009) Körperleben und Körperbild: Ein Handbuch zur Diagnostik (Body Life and Body Image: A Handbook for Diagnosis). Schat- 
tauer, Stuttgart.

[6] Gallagher, S. (2005) How the Body Shapes the Mind. Oxford University Press, New York. http://dx.doi.org/10.1093/0199271941.001.0001

[7] Frostig, M. (1977) Bewegen, Wachsen, Lernen. Bewegungserziehung. 3 Auflage, W.Crüwell Verlag, Dortmund.

[8] O’Sullivan, S., Schmitz, T.J. and Fulk, G.D. (2014) Physical Rehabilitation. 6th Edition, Davis Plus, Philadelphia.

[9] Petermann, F. and Petermann, U. (2010) Einführung in den Hamburg-Wechsler-Intelligenztest für Kinder - IV (HAWIK-IV). Huber, Bern.

[10] Frostig, M., Lefever, D.W. and Whittlesey, J.R.B. (1961) A Developmental Test of Visual Perception for Evaluating Normal and Neurologically Handicapped Children. Perceptual and Motor Skills, 12, 383-394. http://dx.doi.org/10.2466/pms.1961.12.3.383

[11] Frostig, M., Lefever, D.W. and Whittlesey, J.R.B. (1966) Administration and Scoring Manual for the Marianne Frostig Developmental Test of Visual Perception. Consulting Psychologists Press, Palo Alto, CA.

[12] Büttner, G., Dacheneder, W., Schneider, W. and Weyer, K. (2008) Frostigs Entwicklungstest der visuellen Wahrnehmung-2 (FEW-2): Deutsche Fassung des Developmental Test of Visual Perception. Hogrefe, Göttingen.

[13] Reynolds, C.R., Pearson, N.A. and Voress, J.K. (2002) Developmental Test of Visual Perception: Adolescent and Adult. PRO-ED Inc., Austin, TX.

[14] DTVP-A: Developmental Test of Visual Perception-Adolescent and Adult (2002) Cited 18 August 2014. http://www.proedinc.com/customer/productView.aspx?ID=900

[15] De Vignemont, F. (2010) Body Schema and Body Image-Pros and Cons. Neuropsychologia, 48, 669-680. http://dx.doi.org/10.1016/j.neuropsychologia.2009.09.022

[16] Koppitz, E.M. (1972) Die Menschendarstellung in Kinderzeichnungen und ihre psychologische Auswertung. Hippokrates Verlag, Stuttgart.

[17] Schetty, S.A. (1974) Kinderzeichnungen: Eine entwicklungspsychologische Untersuchung. PhD Thesis, Juris Verlag, Zürich.

[18] Krombholz, H. (1993) Händigkeit, Körperschema und kognitive und motorische Leistungen im Kindesalter-eine Literaturübersicht. Schweizerische Zeitschrift für Psychologie, 52, 271-286.

[19] Tarlow, A. (2013) Konduktive Förderung für Kinder und Jugendliche mit Zerebralparese. Books on Demand GmbH, Norderstedt.

[20] Ziler, H. (2000) Der Mann-Zeichen-Test in detailstatistischer Auswertung. Aschendorf, Münster.

[21] Brosat, H. and Tötemeyer, N. (2007) Der Mann-Zeichen-Test nach Hermann Ziler. Aschen dorff, Münster.

[22] Machover, K. (1949) Personality Projection in the Drawing of the Human Figure: A Method of Personality Investigation. Charles C. Thomas, Springfield, IL. http://dx.doi.org/10.1037/11147-000

[23] Krombholz, H. (2008) Zusammenhänge zwischen Händigkeit und motorischen und kognitiven Leistungen im Kindesalter. Zeitschrift für Entwicklungspsychologie und Pädagogische Psychologie, 40, 189-199. http://dx.doi.org/10.1026/0049-8637.40.4.189

[24] Marques de Sá, J.P. (2007) Directional Data. Applied Statistics Using SPSS, STATISTICA, MATLAB and R. Springer, Berlin. http://dx.doi.org/10.1007/978-3-540-71972-4

[25] Oster, G.D. and Crone, P.G. (2004) Using Drawings in Assessment and Therapy: A Guide 
for Mental Health Professionals. Brunner-Routledge, New York.

[26] Jenni, O. (2013) Wie Kinder die Welt abbilden-Und was man daraus folgern kann. Pädiatrie up2date, 8, 227-253. http://dx.doi.org/10.1055/s-0032-1326475

[27] Abercrombie, M. and Tyson, M. (1966) Body Image and Draw-a-Man Test in Cerebral Palsy. Developmental Medicine \& Child Neurology, 8, 9-15. http://dx.doi.org/10.1111/j.1469-8749.1966.tb08267.x

[28] Strauss, R.S. (2000) Adult Functional Outcome of Those Born Small for Gestational Age: Twenty-Six-Year Follow-Up of the 1970 British Birth Cohort. Journal of American Medical Association, 283, 625-632. http://dx.doi.org/10.1001/jama.283.5.625

[29] Schepers, S., Deković, M., Feltzer, M., de Kleine, M. and van Baar, A. (2012) Drawings of Very Preterm-Born Children at 5 Years of Age: A First Impression of Cognitive and Motor Development? European Journal of Pediatrics, 171, 43-50. http://dx.doi.org/10.1007/s00431-011-1476-8

[30] Carroll, J.B. (1993) Human Cognitive Abilities: A Survey of Factor-Analytic Studies. Cambridge University Press, New York. http://dx.doi.org/10.1017/CBO9780511571312

[31] Carroll, J.B. (1997) The Three-Stratum Theory of Cognitive Abilities. In: Flanagan, D.P., Genshaft, J.L. and Harrison, P.L., Eds., Contemporary Intellectual Assessment: Theories, Tests, and Issues, The Guilford Press, New York, 122-130.

[32] Skatvedt, M. (1960) Sensory, Perceptual, and Other Non-Motor Defects in Cerebral Palsy. In: Child Neurology and Cerebral Palsy. Little Club Clinics in Developmental Medicine, Vol. 2, Spastic Society with Heinemann Medical, London.

\section{Submit or recommend next manuscript to SCIRP and we will provide best service for you:}

Accepting pre-submission inquiries through Email, Facebook, LinkedIn, Twitter, etc. A wide selection of journals (inclusive of 9 subjects, more than 200 journals)

Providing 24-hour high-quality service

User-friendly online submission system

Fair and swift peer-review system

Efficient typesetting and proofreading procedure

Display of the result of downloads and visits, as well as the number of cited articles

Maximum dissemination of your research work

Submit your manuscript at: http://papersubmission.scirp.org/

Or contact nm@scirp.org 